\title{
Physical Examination still has the Leading Role: A Case of Bezold's Abscess
}

\author{
Morteza Saeedi, Amirhosein Jahanshir, Farzaneh Shirani, Ehasn Karimi \\ Department of Emergency Medicine, Tehran University of Medical Sciences, Tehran, Iran
}

\section{ABSTRACT}

Introduction: Although Bezold's abscess is rarely seen as a complication of acute otitis media and mastoiditis in the antibiotic era, the number of reported cases has increased in the last 2 decades.

Case Report: In this case report, we present a young man with a large Bezold's abscess, which extended to his lower chest after 2 weeks of misdiagnosis. He underwent surgical treatment along with antibiotic therapy. He was discharged home after 2 weeks in a good condition.

Conclusion: We emphasize on the role of having a high index of suspicion for Bezold's abscess and performing a detailed physical examination in patients with signs and symptoms of acute otitis media and mastoiditis. It is better to have a low threshold for obtaining a computed tomography scan in these patients and diagnose the early stages of this potentially fatal condition.

Keywords: Bezold's abscess, acute mastoiditis, acute otitis media, external ear agenesis, physical examination

Received: 30.05.2015 Accepted: 31.07.2015

\section{Introduction}

A Bezold's abscess, first described by Dr. Friedrich Bezold in late $19^{\text {th }}$ century (1), is a rare complication of bacterial mastoiditis that extends to the extra-periosteal soft tissue of the neck (2). Streptococcus pneumoniae, Haemophilus influenzae, Staphylococcus aureus, and Pseudomonas aeruginosa are the main bacteria that cause Bezold's abscess.

The most important signs and symptoms of the disease are fever, neck pain, restricted neck movements, purulent ear discharge, and tenderness on the mastoid process. An untreated Bezold's abscess can lead to facial and vestibulocochlear nerves compression, facial muscles weakness, and hearing loss. It can also cause fatal complications, including sepsis or bacterial endocarditis.

Here, we present a case of Bezold's abscess in the setting of external ear agenesis that had not been diagnosed in a timely manner and had extended to the patient's lower chest.

\section{Case Report}

A 22-year-old male presented to our emergency department complaining of fever and headache for 20 days. He had an intermittent fever without chills, and his headache was generalized and vague tension type with gradual onset. He was admitted to the hospital in his town and was treated with amoxicillin/clavulanic acid for 7 days. Antibiotic therapy improved his general condition, and he was discharged home with no fever or headache and was administered with cefixime and cinnarizine. Unfortunately, his symptoms recurred the next day, with the addition of neck and right arm pain that caused passive and active limitation of his shoulder and neck range of motion. He came back to the same hospital complaining of swelling over the right lateral aspect of his neck. According to his medical documents, the doctors could not find any obvious difference between the left and right aspects of his neck. They administered amoxicillin again and collected laboratory data to determine the source of possible infection. The results of Hepatitis B Surface antigen ( $\mathrm{HBs}$ Ag), Hepatitis B Surface Antibody (HBs Ab), Hepatitis A Virus Antibody (HAV Ab), Hepatitis C Virus Antibody (HCV Ab), and Human Immunodeficiency Virus Antibody (HIV Ab) were negative, and Hepatitis B Core antibody ( $\mathrm{HBC} A \mathrm{Ab}$ ) was borderline. Liver function tests were in the normal range. They could not determine any source of infection after 7 days and referred him to our hospital.

\section{Address for Correspondence:}

Amirhosein Jahanshir, Department of Emergency Medicine, Tehran University of Medical Sciences, Tehran, Iran

E-mail: ah-jahanshir@sina.tums.ac.ir

(c) Copyright 2016 by Emergency Physicians Association of Turkey - Available online at www.jemcr.org 


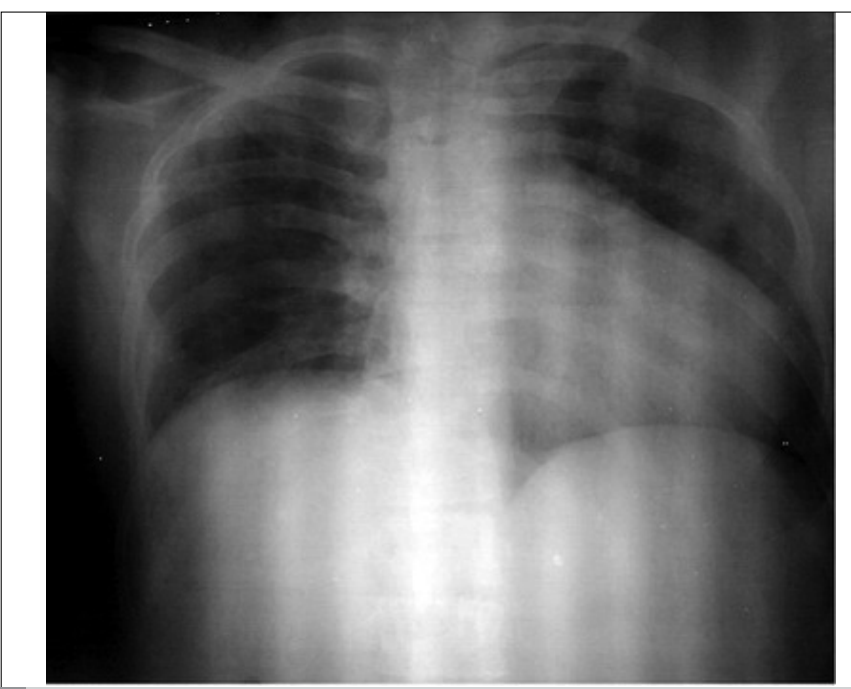

Figure 1. Patient's chest X-ray

In his past medical history, he had a bilateral external ear agenesis and congenital hearing impairments. His habitual history was positive for smoking cigarettes and drinking alcohol. In his physical examination, he had an ill but not toxic appearance. There were a tender swelling on his right anterior chest extending to the right sub-axillary region and an erythematous maculopapular rash on his anterior and posterior chest. His vital signs were as follows: blood pressure, 130/70 $\mathrm{mmHg}$; pulse rate, 86 beats per minute; respiratory rate, 24 breath per minute; and body temperature, $38^{\circ} \mathrm{C}$. His right lateral neck and mastoid were locally tender but not erythematous. Other laboratory findings were as follows: WBC $=26200 / \mathrm{mm}^{3}$, Hemoglobin $=12.7 \mathrm{~g} / \mathrm{dL}, \mathrm{PLT}=136000 / \mathrm{mm}^{3}, \mathrm{PT}=12.5 \mathrm{~s}, \mathrm{PTT}=36 \mathrm{~s}$, $I N R=1$, Blood sugar $=314 \mathrm{mg} / \mathrm{dL}$, Urea $=35 \mathrm{mg} / \mathrm{dL}$, Creatinine $=0.9$ $\mathrm{mg} / \mathrm{dL}, \mathrm{Na}=136 \mathrm{mEq} / \mathrm{L}$, and $\mathrm{K}=4.7 \mathrm{mEq} / \mathrm{L}$.

Chest X-ray showed a few lucent areas on the right hemithorax and supraclavicular regions (Figure 1). On his neck and chest computed tomography (CT) scan, we found the signs of mastoiditis and a large Bezold's abscess, extending from the right mastoid to the right lower chest, and a right side pleural effusion (Figures 2 and 3). The patient underwent three surgical operations in the next 2 weeks by ear-nose-throat surgeons along with administration of intravenous antibiotics (ceftriaxone, vancomycin, and clindamycin). After 2 weeks, he was discharged home, and we found no recurrence on follow-up visits.

\section{Discussion}

Bezold's abscess has become a rare complication of otitis media and acute mastoiditis after the successful treatment of these conditions with antibiotics in the $20^{\text {th }}$ century (3). In a PubMed search for recent cases of Bezold's abscess, we could find less than 40 case reports since 1967, and 24 of them were reported after 2000. An increase in immunocompromised patients [cancer patients on chemotherapy, recipients of organ transplants, and AIDS patients (4)] and emerging antibiotic resistant bacteria may be the cause of this threefold increase in the number of case reports on Bezold's abscess since 2000 .

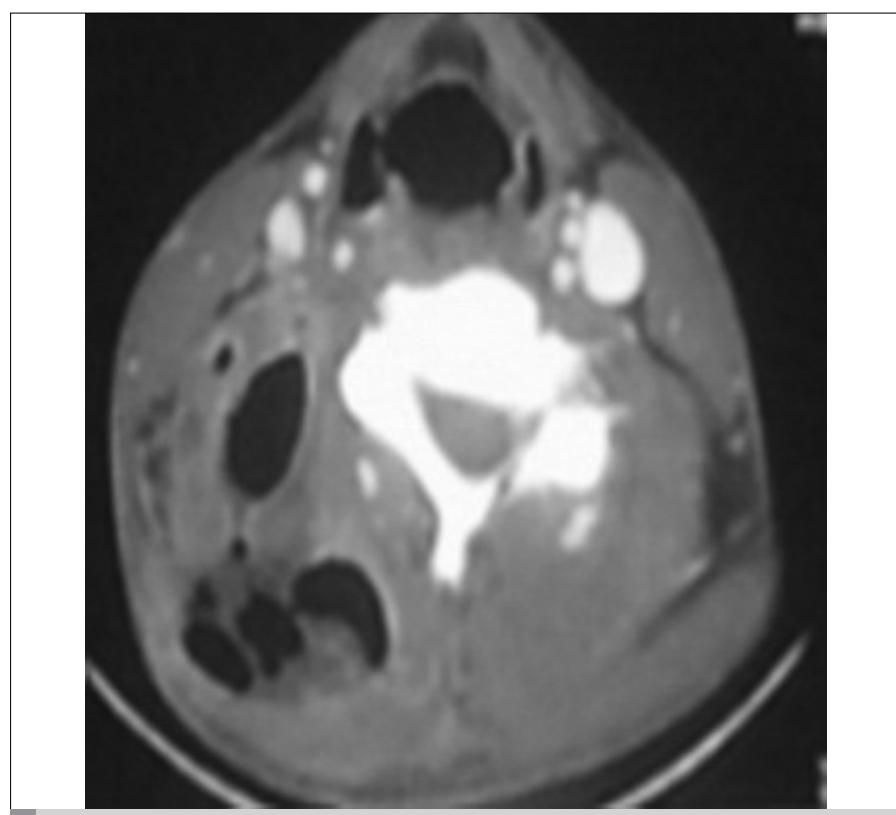

Figure 2. Selected cut of the patient's neck CT scan

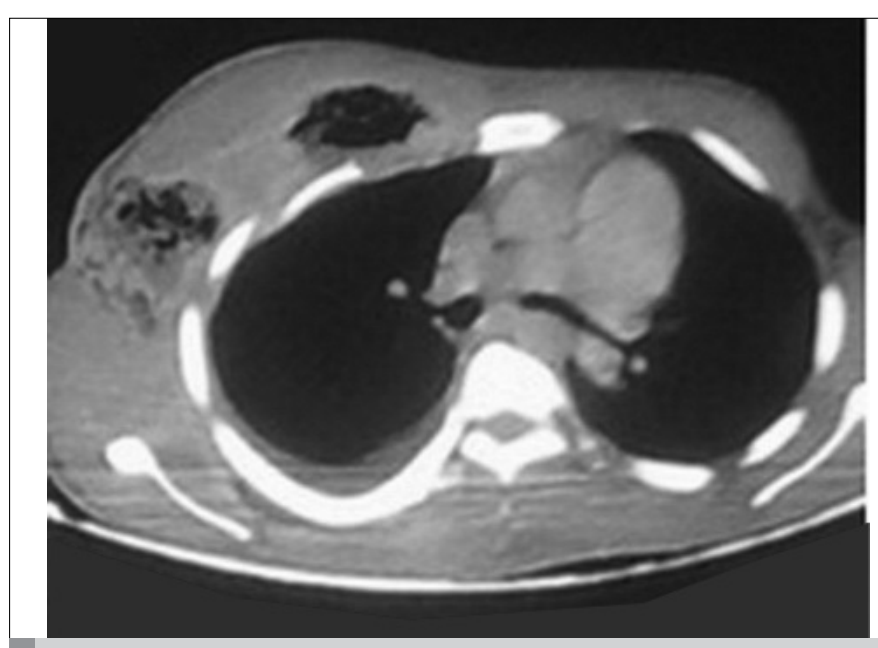

Figure 3. Selected cut of the patient's chest CT scan

In this article, along with reporting the case, we wanted to emphasize on the role of a thorough physical examination for the diagnosis of rare conditions. Unfortunately, in the first 2 weeks, nobody performed a complete physical examination on this patient, and the doctors overlooked an obvious asymmetry on his chest, which could guide them to the diagnosis. Meningitis was the first impression of our residents because of fever, headache, and restricted range of motion of the neck in addition to resistance to administered antibiotics. The rarity of Bezold's abscess was the reason behind the delay in diagnosis, which could be prevented by a thorough physical examination.

A CT scan is the imaging modality of choice in diagnosing and planning for the surgical treatment of Bezold's abscess (5). Because of the rarity of this condition, the key to its diagnosis is to be alert, and it is reasonable to perform a neck CT scan in patients with neck pain and local tenderness over the mastoid process. Ultrasound may also help 
to differentiate lymphadenopathy from abscess in the soft tissue of the neck (6).

Surgical intervention to drain as much pus as possible is the definite treatment of Bezold's abscess, and inpatient intravenous antibiotic therapy is also necessary. The antibiotic of choice depends on the type of involved bacteria. Ceftriaxone or cefepime are used for Streptococcus pneumoniae and gram-negative organisms. Vancomycin and clindamycin may be used for staphylococcus and anaerobes, respectively.

\section{Conclusion}

Although Bezold's abscess is a rare complication of acute otitis media and mastoiditis, its incidence is increasing because of the increasing number of immunocompromised patients and antibioticresistant bacteria. The diagnosis of Bezold's abscess requires a high index of suspicion; therefore, a detailed physical examination and using a diagnostic imaging method are necessary in patients with ear and neck complaints to determine clinical signs of this condition and its potentially fatal complications. The CT scan is the imaging modality of choice for the diagnosis of Bezold's abscess.

Informed Consent: Informed consent was obtained from the patient who participated in this case.

Peer-review: Externally peer-reviewed.
Author contributions: Concept - M.S., A.J.; Supervision - M.S., Materials - E.K.; Literature Search - A.J., F.S.; Writing - A.J., F.S.; Critical Reviews - M.S., E.K.

Conflict of Interest: The authors declare that they have no conflict of interests.

Financial Disclosure: The authors declare that this study has received no financial support.

Acknowledgement: The authors would like to thank the patient and his family members for their permission to publish this case report.

\section{References}

1. Bezold F. Ein neuer Weg für die Ausbreitung eitriger Entzündung aus den Raumen des Mittelohrs auf die Nachbarschaft Deutsche medizinische. Wochenschrift 1881; 28: 381-4. [CrossRef]

2. Yorgancilar E, Yildirim M, Gun R, et al. Complications of chronic suppurative otitis media: a retrospective review. EurArch Otorhinolaryngol 2013; 270: 69-76. [CrossRef]

3. Gaffney RJ, O'Dwyer TP, Maguire AJ. Bezold's abscess. J Laryngol Otol 1991; 105: 765-6. [CrossRef]

4. Patel N, Goodman J, Singh A. Bezold's abscess in the setting of untreated HIV infection. Laryngoscope 2010; 120 Suppl 4: S134. [CrossRef]

5. Castillo M, Albernaz VS, Mukherji SK, Smith MM, Weissman JL. Imaging of Bezold's abscess. AJR Am J Roentgenol 1998; 171: 1491-5. [CrossRef]

6. Secko $M$, Aherne A. Diagnosis of Bezold abscess using bedside ultrasound. J Emerg Med 2013; 44: 670-2. [CrossRef] 